SECTION 2

THERMAL AND FAST REACTOR MATERIALS

https://doi.org/10.46813/2021-132-066

UDC 539.12.04

\title{
FORMATION OF PLASTIC PROPERTIES OF 12Cr18Ni10Ti STEEL HIGHLY IRRADIATED BY NEUTRONS
}

\author{
O.P. Maksimkin ${ }^{1,2}$, D.A. Merezhko ${ }^{1}$, M.S. Merezhko ${ }^{1}$, K.B. Sarsenbayeva ${ }^{1}$ \\ ${ }^{1}$ Institute of Nuclear Physics, Almaty, Republic of Kazakhstan; \\ ${ }^{2}$ National Research Nuclear University "Moscow Engineering Physics Institute”, \\ Moscow, Russia \\ E-mail: maksimkin@inp.kz
}

New results of the experiments on the study of nature and patterns of the effect of anomalously high ductility of austenitic meta-stable irradiated steels are discussed, the possible causes of its formation and the relationship with the deformation "wave" are analyzed, and the recommendations for "wave" modeling are provided in the paper.

\section{INTRODUCTION}

It is well known that the intense effect of radiation on metallic materials causes hardening and embrittlement of austenitic chromium-nickel steels [14]. In this case, the low-temperature $\left(20 \ldots 300^{\circ} \mathrm{C}\right)$ ductility of structural reactor materials as a result of neutron irradiation with a fluence of $>10^{22} \mathrm{n} / \mathrm{cm}^{2}$ can decrease by more than 5-7 times, compared with the non-irradiated materials. At the same time, the analysis of the literature data showed $[5,6]$ that the ductility characteristics of the neutrons irradiated austenitic stainless steels decrease non-monotonically with the growth of the damaging dose, demonstrating several local maxima, the nature of which is under discussion.

Thus, in [5], the unusual dependence of the change in the relative elongation of $\mathrm{Cr} 18 \mathrm{Ni} 10 \mathrm{Ti}$ steel irradiated in the working channel of the RPT nuclear reactor core at $T_{\text {irr }}=100 \ldots 130{ }^{\circ} \mathrm{C}$ on the integral neutron dose has been obtained (see Fig. 1). Upon deformation of the samples irradiated to $1 \cdot 10^{21} \mathrm{n} / \mathrm{cm}^{2}$, a yield area appears in the tensile diagram, and the relative elongation becomes larger than that of steel irradiated with a comparatively lower fluence $\left(1.2 \cdot 10^{20} \mathrm{n} / \mathrm{cm}^{2}\right)$.

Abnormally high values of the ductility characteristics of austenitic steels exposed to a significant effect of accelerated nuclear particles have been recorded by many researchers.

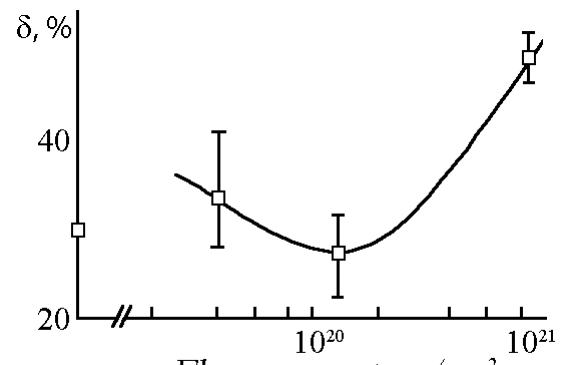

Fluence, neutron $/ \mathrm{cm}^{2}$

Fig. 1. Effect of the integral neutron dose $\Phi t$ (En $>1 \mathrm{MeV})$ on mechanical properties of the neutrons irradiated Cr18Ni10Ti steel at $T_{\text {irr }}=100 \ldots 130{ }^{\circ} \mathrm{C}$,

$$
T_{\text {test }}=20^{\circ} \mathrm{C}[5]
$$

The obtained values for the strength and ductility characteristics of highly irradiated steel samples, known from the literature, are provided in Table 1. It was found that the steel samples are deformed with the formation of a yield area on the tensile diagram, demonstrating the anomalously high ductility for such high damaging doses (Fig. 2).

From Fig. 2, in particular, it follows that the ductility of steel, irradiated to the damaging dose of $43 \mathrm{dpa}$, is higher than that of steel irradiated to $7 \mathrm{dpa}$ (59 and 44\%, respectively).

Effect of the damaging dose and the temperature of neutron irradiation of 12Cr18Ni10Ti steel on its mechanical characteristics at $T_{\text {test }}=20^{\circ} \mathrm{C}$

\begin{tabular}{|c|c|c|c|c|c|}
\hline Reactor & Fluence/damaging dose & $T_{\text {irr. }}{ }^{\circ} \mathrm{C}$ & $\sigma_{0,2}, \mathrm{MPa}$ & $\varepsilon_{\text {total }}, \%$ & $\begin{array}{c}\text { Literature } \\
\text { reference }\end{array}$ \\
\hline RPT & $1 \cdot 10^{21} \mathrm{n} / \mathrm{cm}^{2}$ & $100 \ldots 130$ & 750 & 46 & {$[5],[6]$} \\
\hline BBP-400 & $14.4 \mathrm{cHa}$ & $270 \ldots 290$ & 995 & 17.1 & {$[7]$} \\
\hline BBP-400 & $30.7 \mathrm{cHa}$ & $270 \ldots 290$ & 1065 & 22.1 & {$[7]$} \\
\hline BBP-400 & $43 \mathrm{cнa}$ & $270 \ldots 290$ & 1022 & 17.4 & {$[7]$} \\
\hline BOR-60 & $100 \mathrm{dpa}$ & $320 \ldots 370$ & 1078 & 25.9 & {$[8]$} \\
\hline BOR-60 & $115 \mathrm{dpa}$ & $320 \ldots 370$ & 1113 & 18.5 & {$[8]$} \\
\hline BOR-60 & $120 \mathrm{dpa}$ & $320 \ldots 370$ & 1154 & 38.7 & {$[8]$} \\
\hline
\end{tabular}




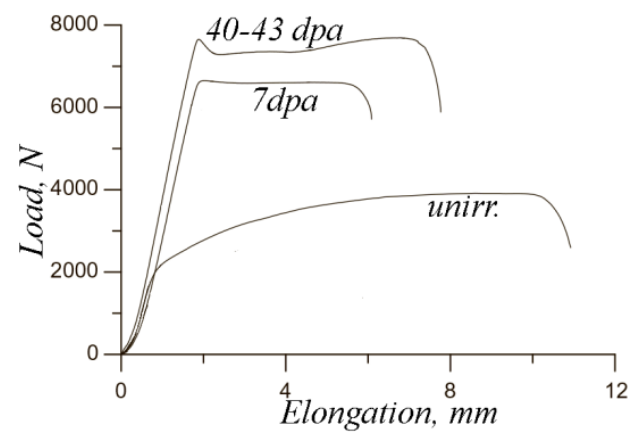

Fig. 2. Tensile diagrams of 12Cr18Ni10Ti steel samples in the non-irradiated state and irradiated with neutrons in the reactor BOR-60 and deformed at $20^{\circ} \mathrm{C}$ [9]

The analysis of the provided data showed that for the neutrons irradiated steel samples, the value of uniform deformation is small and, in many cases, does not exceed $1 \ldots 2 \%$. The section of the diagram, corresponding to the localized deformation development, is well expressed. The obtained experimental curves were divided into two types of different sections of the diagram corresponding to formation and development of the neck. The first type: the values of the load beyond the ultimate strength, depending on the degree of deformation, monotonically decrease. The second type of curves is when tensile diagrams contain a continuous yield area.

Subsequently, as a result of systematic studies of the changes in the structure and properties of structural materials of the spent fuel assemblies (FA) ducts of the nuclear reactor $\mathrm{BN}-350$, which has been in operation for more than 25 years at the coolant temperatures $\left(280 \ldots 450{ }^{\circ} \mathrm{C}\right)$ and the damaging doses up to $1.2 \cdot 10^{-6} \mathrm{dpa} / \mathrm{s}$, a new experimental fact was discovered formation of the "phase transformation wave" during cold deformation in the highly irradiated ( $60 \mathrm{dpa})$ austenitic chromium-nickel corrosion-resistant steels [10-12]. It was suggested [13] that movement of the "wave" leads to a relatively high ductility of the irradiated reactor steel. It can be realized if the level of internal stresses, formed under certain specific parameters of heat treatment, irradiation, and deformation conditions of meta-stable austenitic steel, reaches the values equal to or greater than the critical stress of the $\alpha$-phase nucleation and leading to manifestation of some optimal intensity of the martensitic $\gamma \rightarrow \alpha$ transformation.

To test this hypothesis, in this work, a special series of experiments were performed on static tension of austenitic reactor steel in the temperature range from -100 to $+20{ }^{\circ} \mathrm{C}$. New results of the experiments on the study of nature and patterns of manifestation of the effect of anomalously high ductility of austenitic meta- stable irradiated steels are provided and discussed, the possible reasons for its formation and the relationship with the "wave" are analyzed, and recommendations for the "wave" modeling are formulated.

\section{EXPERIMENTS}

We studied $12 \mathrm{Cr} 18 \mathrm{Ni} 10 \mathrm{Ti}$ steel and $\mathrm{Cr} 18 \mathrm{Ni}$ steel for comparison, the samples of which were preliminarily heat treated by heating to various temperatures $\left(T_{\text {anneal }}\right): 650,700,800,900$, and $1050{ }^{\circ} \mathrm{C}$, holding for $30 \mathrm{~min}$ at each temperature and cooling in water. Mechanical tests were performed on the setup Instron-1195 with simultaneous recording of machine tensile diagrams and subsequent determination of magnetization of the deformed samples using the flux gate Feritscope MP-30.

On all prepared "load-elongation" diagrams, with the exception of those corresponding to heat treatment at $1050{ }^{\circ} \mathrm{C}$ for $30 \mathrm{~min}$, a "yield area" was observed, which was preceded by a yield "tooth" [14].

In the experiments on determination of the strength and ductility characteristics of $12 \mathrm{Cr} 18 \mathrm{Ni} 10 \mathrm{Ti}$ austenitic steel samples subjected to mechanical-thermal treatment before irradiation: $18 \ldots 20 \%$ cold deformation + annealing $800{ }^{\circ} \mathrm{C}, 1$ hour, irradiated with neutrons in the reactor $\mathrm{BN}-350$ up to $55 \mathrm{dpa}$, we have also established [15] that at room temperature and the strain rate $V=9 \cdot 10^{-4} \mathrm{~s}^{-1}$, they change shape with formation of a yield area on the tensile diagram, demonstrating an anomalously high ductility for such large damaging doses ( 20\%) (Fig. 3).

The results of processing the tensile diagrams of austenitic steel are shown in Table 2.

Analysis of the engineering tensile diagrams enabled us to determine the length of the yield area (the section of "wave" distribution), as well as the dependence of this value on the state of material and the test temperature (Fig. 4).

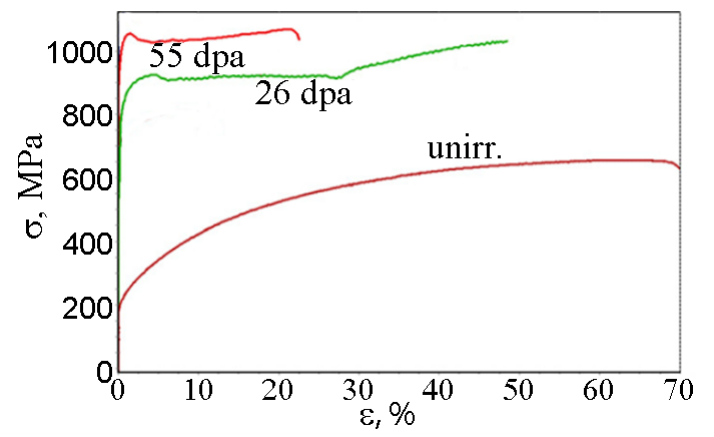

Fig. 3. Engineering diagrams for 12Cr18Ni10Ti steel samples non-irradiated and irradiated in the reactor $B N-350$ [15]

Influence of the damaging dose and irradiation temperature on the strength and ductility of 12Cr18Ni10Ti steel

\begin{tabular}{|c|c|c|c|c|c|}
\hline $\begin{array}{c}\text { Reactor, elevation in mm } \\
\text { from the center of active zone }\end{array}$ & $\begin{array}{c}\text { Damaging dose, } \\
\mathrm{dpa}\end{array}$ & $T_{\mathrm{irr}}{ }^{\circ} \mathrm{C}$ & $\sigma_{0.2}, \mathrm{MPa}$ & $\varepsilon_{\text {total}}, \%$ & $\begin{array}{c}\text { Literature } \\
\text { reference }\end{array}$ \\
\hline Initial state & 0 & - & 302 & 36.5 & This work \\
\hline BN-350, CC-19, “+500" & 26.5 & 423 & 780 & 18.5 & {$[10]$} \\
\hline BN-350, CC-19, “+300" & 46.6 & 405 & 790 & 16 & {$[16]$} \\
\hline BN-350, CC-19, “-160” & 55.7 & 330 & 960 & 22 & {$[13]$} \\
\hline BN-350, CC-19, “0” & 58.9 & 350 & 780 & 12 & {$[13]$} \\
\hline
\end{tabular}




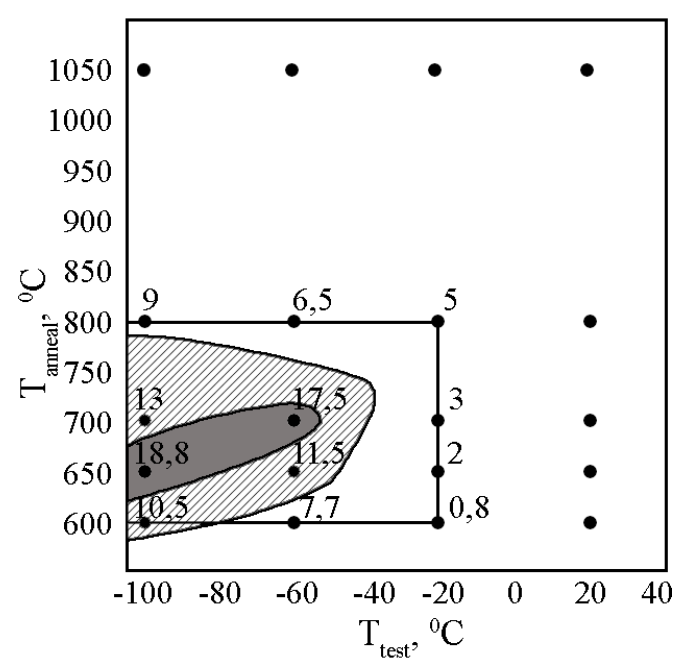

Fig. 4. Dependence of the "yield area" length (deformation associated with the "wave" movement) on the test temperature and the state of material. The numbers at the points indicate the length of the plastic deformation area in the engineering diagram in $\%$, the area with diagonal shading - the yield area length from 10 to $15 \%$, the gray area - the yield area length value of more than $15 \%$ [17]

Fig. 4 shows that the greatest value of the yield area in the studied range of tensile temperatures was observed after heat treatment at the temperature of $650{ }^{\circ} \mathrm{C}$ and deformation at $-100{ }^{\circ} \mathrm{C}$. Probably, the absolute maximum length of the "yield area" can be achieved by heat treatment at $675^{\circ} \mathrm{C}$ and the test temperatures from -60 to $-80{ }^{\circ} \mathrm{C}$, but this assumption needs to be verified.

Metallographic and electron microscopic studies of changes in the microstructure of $12 \mathrm{Cr} 18 \mathrm{Ni} 10 \mathrm{Ti}$ steel samples after irradiation in the reactor BN-350 and subsequent tests for uniaxial tension have revealed a number of common and distinctive features. Fig. 5 shows the microstructure of the neutron-irradiated (12.3 dpa) sample for the non-deformed and deformed (localized) regions. The micro-neck area is characterized by the presence of a plurality of slip packs in the grains, and several intersecting slip systems can be found in the crystallographically favorably oriented grains. At the same time, in the samples irradiated to the higher damaging dose $(55.7 \mathrm{dpa})$, for which the yield area was recorded, the slip lines were practically not revealed.

It was found that in the process of stretching of the highly irradiated steel samples, the formation and accumulation of the martensitic $\alpha$-phase is observed, which is concentrated mainly in the neck zone, and its amount increases with the growth of the deformation degree. For example, in a steel sample (CC-19, “-160 mm"), irradiated up to $55 \mathrm{dpa}$ and deformed at room temperature, in a zone with a local deformation of $30 \ldots 35 \%$, the volume content of the magnetic phase is $V \alpha=35 \%$.

The experiments have shown that when the steel sample is stretched, the "wave" moves from one end of the sample to the other, resulting in additional strengthening of the deformed material due to the formation of a ferromagnetic martensitic $\alpha$-phase.
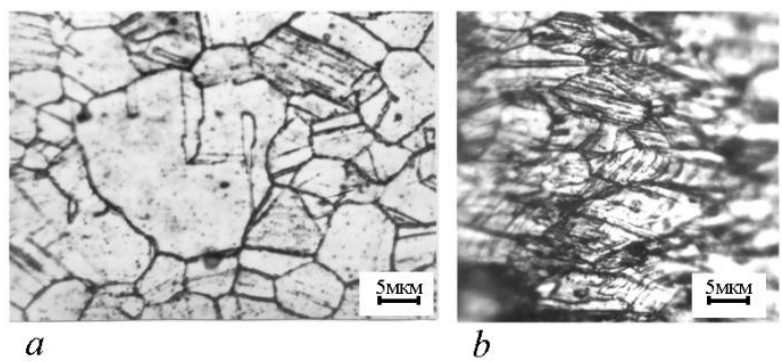

Fig. 5. Microstructure of the sample $(a, b)$ of

$12 \mathrm{Cr} 18 \mathrm{Ni10Ti}$ steel irradiated with neutrons in the reactor $B N-350\left(12.28 \mathrm{dpa}, T_{\text {irr }}=313^{\circ} \mathrm{C}\right)$ and deformed at $20^{\circ} \mathrm{C}$ :

$a$-non-deformed area; $b$ - the area near the destruction zone (microneck)

In [17], it was emphasized that the qualitative difference between the phase transformation wave, considered in the highly irradiated materials from a similar phenomenon described earlier in the literature for the non-irradiated metals and alloys, is mainly the magnitude of the deformation amplitude. In the "phase transformation wave", the local value of the deformation amplitude is $30 . .35 \%$ for austenitic steel irradiated with fast neutrons to a damaging dose of $60 \mathrm{dpa}$. For comparison, the Chernov-Luders band at the yield area during iron deformation has an average amplitude of maximum $4 \ldots 6 \%$, and the "strain waves" in the non-irradiated metal polycrystals (see, for example, [16]) have a strain amplitude of the order of fractions of a percent or less.

The morphology of the "phase transformation wave" in the highly irradiated steel 12Cr18Ni10Ti has been studied. It was established that during formation of the wave it moves along the deformed sample not immediately with a flat continuous front, but gradually in the form of separate wedge-shaped sections (Fig. 6).
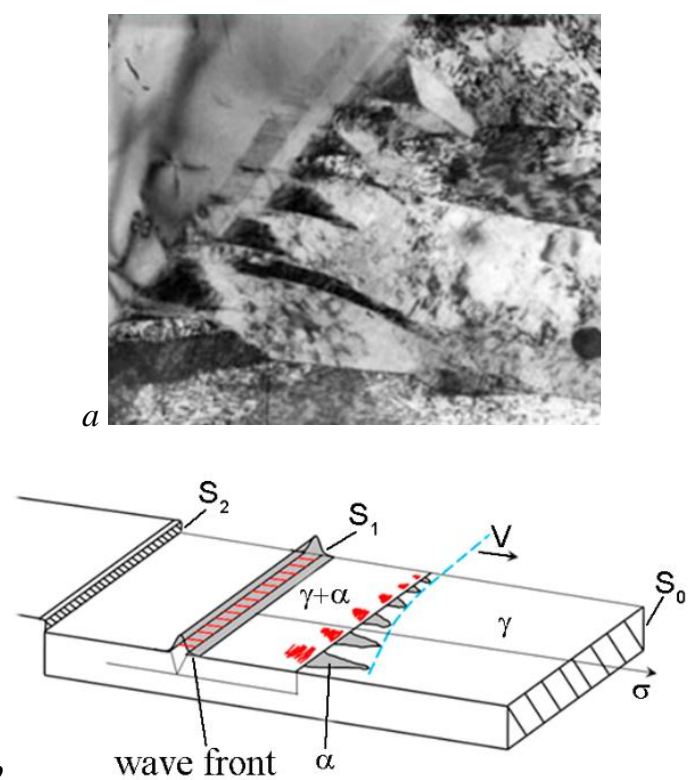

Fig. 6. Martensitic formations (a) [18] in the wave front of the deformed sample of $12 \mathrm{Cr} 18 \mathrm{NilOTi}$ steel $(b)$ 
The phase $\gamma \rightarrow \alpha$ transformation occurs in them, and, moreover, the nuclei of the martensitic $\alpha$-phase wedge into the $\gamma$-phase at an acute angle and, with further stretching of the sample, expand and merge into strips, leaving behind a strengthened two-phase $(\gamma, \alpha)$ region.

In almost all tested steel samples, it was observed that in the center of the formed macro-neck at the stage of pre-fracture, a visually well-visible secondary microneck $400 \ldots 700 \mu \mathrm{m}$ wide is formed. It was also found that in the fracture zone of the samples, the microhardness slightly increases.

\section{DISCUSSION OF RESULTS}

\section{Abnormally high values of ductility of the highly irradiated steels}

The experimental results, presented recently in the scientific literature, indicate that the reactor austenitic steels are capable of exhibiting abnormally high ductility properties even after very high radiation doses (up to $150 \mathrm{dpa}$ ), some types of heat treatment and the post-radiation test parameters.

These data $[5,10]$ stand out significantly against the background of widespread results indicating a sharp decrease in ductility (up to $12 \ldots 2 \%$ ) with the growth of the radiation dose, and the detection of the so-called phenomenon of low-temperature $\left(20 \ldots 300{ }^{\circ} \mathrm{C}\right)$ radiation embrittlement of reactor austenitic steels [2, 3]. Table 2 summarizes the author's data on the effect of neutron irradiation on the ductility of $12 \mathrm{Cr} 18 \mathrm{Ni} 10 \mathrm{Ti}$ steel. Tables 1 and 2 show that when the reactor steel is exposed to large neutron fluxes, leading to significant damage $(23 \ldots 150 \mathrm{dpa})$ of the material, the ductility values remain relatively high. It is natural to assume that the root cause of this behavior is the radiation changes in the phase composition, microstructure and the associated internal stress state of steel.

\section{Strain bands and internal stresses}

It was found that when pre-polished samples of iron and steel are stretched, their surface becomes dull, which is explained by the formation of microscopic irregularities as a result of elastic stresses wave propagation. It was shown that concave lines, associated with local depressions on the surface, are formed as a result of the action of tensile stress waves $(\sigma+)$, and convex ones - with the action of compressive stresses $(\sigma-)$.

It is believed that under intense mechanical stress from the outside, the non-irradiated solid polycrystalline body spontaneously stratifies into alternating, actively deforming and non-deforming zones (stripes) of the material, which, accordingly, can move along the working length of the sample or be motionless $[19,20]$. The result of the successive involvement of new nondeformed regions of the sample in the stretching process is high ductility of many metals and alloys. Peculiar deformation bands were observed in both non-irradiated and irradiated steel samples. For example, in the nonirradiated austenitic chromium-nickel steel, the strips were usually sparse and resembled small necks of the localized flow. Once formed, each such "running" neck [21] develops as a "stable" neck, but then (when, as a result of the $\gamma \rightarrow \alpha$ transformation, enough $\alpha$-phase is formed for the material to harden), its development fades out and another, the same micro-neck is formed nearby, but already at high values of stresses and strains. The distance between these stripes - necks - is relatively large (Fig. 7,a). Irradiated steel also contains the deformation bands, but they, apparently, cannot develop for too long in a hardened matrix. That is why they are usually narrow, but there are many of them, and they are located more often than in the non-irradiated steel (see Fig. 7,b). In this case, in order for the deformation to pass from one strip to another, it is not necessary to have a too large amount of hardening (i.e., the movement of the wave of plastic deformation occurs at an almost constant stress $\sigma$ ), therefore, a plateau (yield area) is formed on the tension diagram " $\sigma-\varepsilon$ ".

So, waves can be considered as the final result of the moving, failed, "unstable" necks, in which the same processes occur as in the "running" necks. The only difference is that the strain-induced $\gamma \rightarrow \alpha$ transition, characterized by certain intensity, does not allow the neck to develop to failure in one place. The concentration of elongation in this localized region of the sample does not occur due to its strengthening and movement of deformation to the neighboring place.

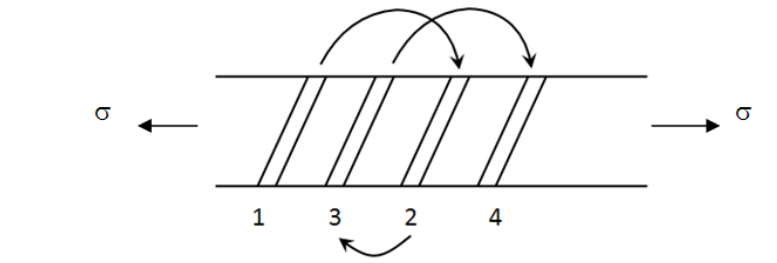

$a$

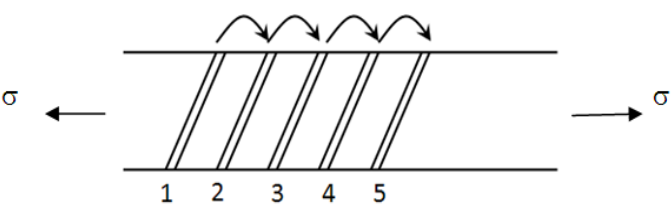

$b$

Fig. 7. Movement of the deformation bands under tension of non-irradiated $(a)$ and irradiated $(b)$ samples of meta-stable austenitic steel (diagram)

This place is "prepared" by previous deformation processes and the stresses in it can become large enough to initiate the $\gamma \rightarrow \alpha$ transition, which at first proceeds with the increasing rate, but with the appearance of compressive stresses (due to the fact that the formed $\alpha$ phase occupies a larger volume than the initial $\gamma$-phase), the $\gamma \rightarrow \alpha$-phase transition slows down and the deformation tends to zero due to significant strengthening of the crystal lattice with a large amount of the formed $\alpha$-martensite. As a result, the deformation processes continue in a neighboring place, where all the events, described above, are repeated (Fig. 8).

Thus, the quasi-uniform formation of the deformation bands occurs, which coincides with the start of the $\gamma \rightarrow \alpha$ transition in the process of plastic deformation of austenitic steel at a certain in the evolution of the defect structure. If, the optimal combination of the degree of radiation damage to the structure, the austenitization and testing temperature is observed, then in such a peculiar stress field a "phase 
transformation wave" is formed - a gradual, continuous movement of the deformation strip along the working part of the deformed sample of meta-stable steel.

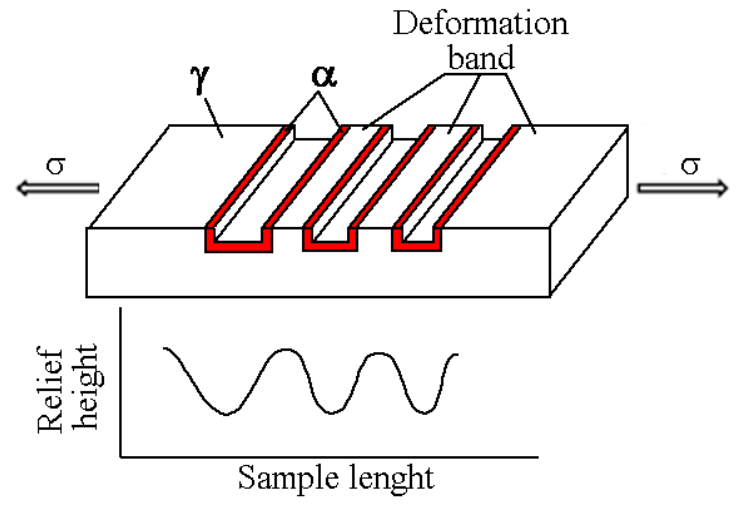

Fig. 8. Diagram of formation and movement of the "phase transformation wave" in the sample of irradiated meta-stable stainless steel under the action of tensile stresses

It follows from the above that the high ductility observed in some radiation experiments is also provided by the action of the wave mechanism of plastic deformation, which is a combined course of two processes of micro- and macrophenomena aimed at ensuring the movement of a mass of material with a certain value and rate: 1) formation and development of the deformation band; 2) continuous movement of several such bands, organizing the waves of the phase transition.

It does not seem controversial to assume that the degree of influence of the deformation-induced $\alpha$-phase on the characteristics of the wave depends not only on the amount of a stronger (than $\gamma$-phase) martensite phase, but also on the "quality" (shape and size) of this phase. To ensure high ductility, it is necessary that the $\alpha$-phase is formed just enough only for strengthening of the crystal lattice and does not allow the deformation strip to deepen intensively, which can lead to embrittlement of the sample. That is, movement of atoms during tension should be oriented along the action of the external force, or, in other words, in order for the ductility to be high, it is necessary that the width of the deformation band (neck) increases faster than its depth grows.

The comparative review of the presented above experimental results allowed us to make the following conclusions.

In order for the "wave" to form during stretching of the neutron-irradiated austenitic chromium-nickel steel, it is necessary that the value of the yield point be close to the value of the critical stress of the $\alpha$-phase formation in the steel $\left(\sigma_{\mathrm{кp}} \approx 685 \mathrm{MPa}\right)$. If plastic deformation begins earlier than the $\gamma \rightarrow \alpha$ transition is initiated, then the yield area in the tension diagram will not be formed (i.e., there will be no "wave"). In general, in order to establish the necessary conditions for the wave formation, it is necessary to consider that the material has high internal stresses already at the start of mechanical tests sufficient for the $\gamma \rightarrow \alpha$ transition to begin immediately after the start of tension, i.e., high internal tensile stresses can form during heat treatment (hardening). If the value $T_{\text {aust }}$ was high enough, then it is necessary to cool the heated sample to lower, negative temperatures, and as a result we will be able to achieve the same stresses that, in the case of "low-temperature" deformation of steel, would have been obtained as soon as the steel sample began to elongate (Table 3).

Austenitization of steel leads to compression of the grain matrix and to stretching of the material in the near-boundary region - the higher the austenitization temperature, the deeper the potential "pit" of the thermally induced stresses (lower yield stress, but higher thermal compressive stresses during quenching). With further stretching, a greater stress shall be applied before the $\gamma \rightarrow \alpha$ transformation occurs.

It follows that low test temperatures are required in order to form a yield area ("wave") during stretching of the irradiated steel. However, in some experiments during testing of the samples irradiated in the reactor $\mathrm{BN}-350$, the internal tensile stresses were so high that it was not necessary to pre-cool the sample and the "wave" of deformation was noticed in it already at the start of tension (yield area in the tension diagram) [14].

Summarizing the above, we can come to the conclusion that the stresses, corresponding to the formation of the yield area, depend both on the temperature of the preliminary heat treatment and on the test temperature. If, due to irradiation, the internal longrange compressive stresses are increased to the values, achieved by changing the temperatures of testing austenitization, then the yield area ("wave"!) can be obtained, i.e. the necessary condition for formation of the phase transition wave is the achievement of such values of internal stresses, the value of which is equal to the critical stress $\left(\sigma_{\mathrm{cr}}\right)$, corresponding to the start of the $\alpha$-phase formation or localization of deformation (in the form of the stable neck formation).

In other words, for initiation of the phase transition wave in the deformed sample, the $\gamma \rightarrow \alpha$ transformation shall start immediately upon reaching the plastic flow stress, i.e., so that the relation $\sigma_{0.2} \approx \sigma_{\mathrm{cr}}$ is fulfilled. On the other hand, in order for the formed wave to move continuously along the working length of the sample (providing high ductility of the material), it is necessary that the intensity of the $\gamma \rightarrow \alpha$ transition be some optimal.

Table 3

Influence of the heat treatment and testing temperature on the values of the yield strength of $\mathrm{Cr} 18 \mathrm{Ni} 9$ steel

\begin{tabular}{|c|c|c|c|c|c|c|c|}
\hline \multicolumn{2}{|c|}{ Heat treatment temperature, ${ }^{\circ} \mathrm{C}$} & 600 & 650 & 700 & 800 & 1050 & 1150 \\
\hline \multirow{2}{*}{ Yield point, $\mathrm{MPa}$} & at $T_{\mathrm{def}}=20^{\circ} \mathrm{C}$ & 1470 & 610 & 590 & 400 & 345 & \multirow{2}{*}{ No area } \\
\cline { 2 - 8 } & at $T_{\mathrm{def}}=-100^{\circ} \mathrm{C}$ & 1765 & 835 & 785 & 580 & 360 & \\
\hline
\end{tabular}

It is natural to assume that by reducing the temperature of heat treatment and testing to negative values it is possible to simulate the formation and movement of the waves in the highly irradiated steel. 
This follows from the fact that the boundary regions play an important role in the initiation of the $\gamma \rightarrow \alpha$ transition during deformation, since upon irradiation, short-range tensile stresses are formed in the grain matrix, and compressive stresses are formed in the nearboundary regions. Upon cooling, long-range compressive stresses are also formed in the matrix, while tensile stresses are formed in the border regions, which contribute to the formation of a "looser" $\alpha$-phase along the grain boundaries. The above is confirmed by the results of mechanical tests of Cr18Ni9Ti steel, provided in Table 3.

\section{Intensity of the $\gamma \rightarrow \alpha$ transformation process during deformation and its relationship with the displacement of the "phase transition wave"}

As mentioned above, the "phase transition waves" (in contrast to the "deformation waves", which are observed in almost all non-irradiated metallic materials and constitute a necessary element of plastic deformation of the non-irradiated materials [10]), are recorded in austenitic reactor steels only after high-dose irradiation (high internal stresses) and only at some optimal intensity of the $\gamma \rightarrow \alpha$ transition.

In general, the intensity of the $\gamma \rightarrow \alpha$ transformation in steel is influenced by: chemical composition, austenitization parameters, temperature and test rate, and also degree of irradiation [9, 22]. Irradiation with neutrons (the reactor WWR-K) intensifies the $\gamma \rightarrow \alpha$ transition during stretching at room temperature, but if irradiated for too long, this can lead to embrittlement of steel. At the same time, high-dose irradiation (the reactor $\mathrm{BN}-350)$ and subsequent deformation at cryogenic temperatures $\left(-60 \ldots-100^{\circ} \mathrm{C}\right)$ reduce the intensity of the $\gamma \rightarrow \alpha$ transition [13]. In some cases, a decrease in intensity to a certain optimal value causes the appearance of a phase transition wave, which, in turn, forms a relatively high ductility.

The reason for this behavior of the deformed metastable steel may be a significant change in internal stresses: cooling to cryogenic temperatures leads to compression of the crystal lattice (tension in the boundary zones) and, consequently, to a decrease in the possibilities of the $\gamma \rightarrow \alpha$ transition in the crystallite matrix. At the same time, high-dose irradiation leads to the formation of long-range compressive stresses, which strengthen the crystal lattice, and short-range tensile stresses (due to high concentration of vacancies!), resulting in the stretching of the lattice in the grain matrix, which has a positive effect on the $\gamma \rightarrow \alpha$ transition in this area.

As it was established above, the $\gamma \rightarrow \alpha$ transformation occurs in the wave front (i.e., the stress level is relatively high $\sim 700 \ldots 1000 \mathrm{MPa}$ ), and the maximum of the transformation falls on the wave crest, which has been subjected to deformation $\Delta l_{\text {samp }} / l_{0}$, where $l_{\text {samp }}$ is the elongation of the sample, $l_{0}$ is the initial sample length.

If the deformation of the lattice in the wave itself (geometric softening) lasts exactly the time that is necessary for the material before its front to harden enough to compensate for its softening, then the wave will quickly move to the neighboring position and this will increase the elongation of the sample.

That is, in order to provide high ductility of steel, the wave shall be small (small h) and rare (large $\omega$ ), and for this purpose it is necessary that the intensity of the formation of the $\alpha$-phase is optimal, such that a lot of strong $\alpha$-phase rapidly could accumulate in the wave front, which promotes the propagation of deformation along the tension axis and prevents early localization. This statement is confirmed by the data of [23, 24], which showed a significant increase in the plasticity of the austenitic steel Kh18N10T due to the special introduction of nuclei of the martensite phase.

\section{CONCLUSION}

Based on the analysis of experimental results, it can be assumed that the anomalously high ductility of austenitic steels, observed in some radiation experiments, is supported by the action of the wave mechanism of plastic deformation, which is a combined course of the processes of micro- and macro-phenomena that contribute to the provision of the directed flow of atoms, resulting in formation and development of the deformation bands, which continuous movement forms the phase transition wave upon further stretching of the sample.

The hypothesize was stated that the main reason for the observed effect is the possibility of the martensitic $\gamma \rightarrow \alpha$ transformation in a deformed meta-stable steel. For the material, highly irradiated by neutrons, the kinetics of the phase transformation and the degree of strain hardening may differ from that of the nonirradiated or weakly irradiated (up to $1 \mathrm{dpa}$ ) steel.

In order for the ductility of the meta-stable reactor steel during stretching to remain high after irradiation, the following conditions shall be met:

- The formation of a stronger $\alpha$-phase in the $\gamma$ lattice should not start early, but not too late in terms of the stretching time, i.e., the critical stresses and deformations at the start of the $\gamma \rightarrow \alpha$ transition $\left(\sigma_{\mathrm{cr}}\right.$ and $\left.\varepsilon_{\mathrm{cr}}\right)$ should also be some definite, optimal values.

The results of numerous experiments indicate that in order for the wave to originate, it is necessary to reach the level of internal stresses corresponding to the start of the $\gamma \rightarrow \alpha$ transformation (i.e., $\sigma_{0.2} \approx \sigma_{\mathrm{cr}} \approx 700 \mathrm{MPa}$ ).

If the internal stresses are higher (close to $1000 \mathrm{MPa}$ ), then the localization of deformation quickly occurs and the wave does not have time to move: (for example, this happened in the case of neutron irradiation of $12 \mathrm{Cr} 18 \mathrm{Ni} 10 \mathrm{Ti}$ steel up to the fluence of $1.3 \cdot 10^{20} \mathrm{n} / \mathrm{cm}^{2}$ and tension at $\left.-100{ }^{\circ} \mathrm{C}[13]\right)$.

- In order for the wave, having originated, to easily move and at the same time the ductility of the irradiated meta-stable austenitic steel remains relatively high, the intensity of the $\gamma \rightarrow \alpha$ transition in the deformed sample shall be some optimal at all stages of the defect structure evolution (in the areas of uniform and localized deformation).

In turn, since the value of intensity is determined by a set of parameters $(\Phi t, T, V$, etc.) that provide a certain level of internal stresses, then, as follows from the above data, the "phase transition wave" can be 
purposefully stimulated, for example, by reducing the test temperature below $20{ }^{\circ} \mathrm{C}$.

Negative temperatures, compressing the crystal lattice of the grain matrix and increasing the internal tensile stresses in the boundary regions, also increase the intensity of the $\gamma \rightarrow \alpha$ transition in the latter - a necessary condition for the wave to form rapidly and move rapidly (in accordance with the rate of deformation). Thus, it can be concluded that the "phase transition wave" in both non-irradiated and irradiated meta-stable austenitic steel can be purposefully stimulated by lowering the test temperature to negative values.

This work was supported by the Grant awarded by the Ministry of Education and Science of the Republic of Kazakhstan: AP08052488

\section{REFERENCES}

1. J. Kim, T. Byun. Analysis of tensile deformation and failure in austenitic stainless steels: Part II Irradiation dose dependence // J. Nucl. Mater. 2010, v. 396, p. 10-19.

2. G.S. Pisarenko, I.R. Kiselevskiy. Strength and ductility of materials in radiation flows. Kiev: "Naukova dumka", 1979, 284 p.

3. L.M. Zabudko, D.I. Likhachev, A.A. Proshkin. Efficiency of fuel assemblies of fast reactors // Physics and technology of nuclear reactors. M.: "Energoatomizdat", 1988, N 35, 168 p.

4. A.M. Parshin, A.P. Petkova. Low-temperature radiation embrittlement and degeneration of deformation capacity of austenitic steels and alloys // Metalls. 2001, N 3, p. 123-127.

5. A.N. Lapin, V.A. Nikolaev, N.A. Razov. Mechanical properties of Cr18Ni10Ti steel after neutron irradiation and their recovery during annealing // Physics and Chemistry of Material Processing. 1970, N 1, p. 8-13.

6. V.D. Yaroshevich, A.N. Lapin. On the influence of neutron irradiation on the ductility characteristics of metals // Problems of Strength. 1977, N 5, p. 90-93.

7. B. Margolin et al. Mechanisms of plastic deformation and fracture of austenitic chromium-nickel steel irradiated during 45 years in WWER-440 // Journal of Nuclear Materials. 2021, v. 549, p. 152911.

8. B.J. Margolin, A.A. Sorokin, V. Shvetsova, A. Minkin, et al. The radiation swelling effect on fracture properties and fracture mechanisms of irradiated austenitic steels Part 1: Ductility and fracture toughness // J. Nucl. Mater. 2016, v. 480, p. 52-68.

9. A.A. Sorokin, B.J. Margolin, et al. Effect of neutron irradiation on tensile properties of materials for pressure vessel internals of WWER type reactors // $J$. Nucl. Mater. 2014, v. 444, p. 373-384.

10. O.P. Maksimkin, O.V. Tivanova, N.S. Silnyagina Peculiarities of the processes of structuralphase transformations and deformation at the stage of pre-fracture of the samples of neutrons irradiated 12Cr18Ni10Ti stainless steel // Proceedings of the $5^{\text {th }}$ International Conference "Nuclear and Radiation Physics”. 2006, v. 2, p. 408-417.
11. M.N. Gusev, O.P. Maksimkin, D.A. Toktogulova A new physical phenomenon in highly irradiated stainless steels - "waves of plastic deformation" - and its practical use // Bulletin of NNC $R K .2008$, N 4, p. 27-33.

12. O.P. Maksimkin, M.N. Gusev, D.A. Toktogulova. Waves of plastic deformation during deformation of the samples of $12 \mathrm{Cr} 18 \mathrm{Ni} 10 \mathrm{Ti}$ stainless steel, irradiated to 26-55 dpa in the reactor BN-350 // Bulletin of higher educational institutions. Series "Physics". 2008, N 3, p. 78-84.

13. O.P. Maksimkin. Phase transformation wave in deformable austenitic steels irradiated in the reactor BN-350 and the conditions for its implementation // Letters to JTF. 2018, v. 44, issue 14, p. 13-18.

14. S.V. Ruban, O.P. Maksimkin, M.N. Gusev, S.V. Rybin. Experimental study of the "deformation wave" in non-irradiated and neutron-irradiated meta-stable steel 12Cr18Ni10Ti // Bulletin of NNC RK. 2010, N 2, p. 25-30.

15. O.P. Maksimkin, M.N. Gusev. Deformationplastic behavior of highly irradiated stainless steels $12 \mathrm{Cr} 18 \mathrm{Ni10Ti}$ and $08 \mathrm{Cr} 16 \mathrm{Ni11 \textrm {M } 3}$ in the range of cryogenic and high temperatures // Physics of Metals and Metal Science. 2010, v. 110, N 5, p. 524-529.

16. M.N. Gusev, O.P. Maksimkin, I.S. Osipov, and Garner F.A. A new and unusual deformation behavior observed in $12 \mathrm{Cr} 18 \mathrm{Ni} 10 \mathrm{Ti}$ stainless steel irradiated at $307^{\circ} \mathrm{C}$ to $55 \mathrm{dpa}$ in $\mathrm{BN}-350 / /$ Proceedings of $13^{\text {th }}$ National Conference on Fusion Reactor Materials. France. 2007, p. 362-368.

17. M.N. Gusev, O.P. Maksimkin, F.A. Garner. Peculiarities of plastic flow involving "deformation waves" observed during low-temperature tensile tests of highly irradiated $12 \mathrm{Cr} 18 \mathrm{Ni} 10 \mathrm{Ti}$ and $08 \mathrm{Cr} 16 \mathrm{Ni} 11 \mathrm{Mo} 3$ steels // J. Nucl. Mater. 2010, v. 403, p. 121-125.

18. O.P. Maksimkin, K.V. Tsai, N.V. Shcherbinina. Investigation of martensitic $\gamma \rightarrow \alpha$-transformation in austenitic stainless chromium-nickel steel implanted with helium // Problems of Atomic Science and Technology. Series "Thermonuclear Fusion", 2003, N 2, p. 73-79.

19. L.B. Zuev. Elastoplastic invariant of solids deformation // Deformation and destruction of materials. 2013, N 2, p. 2-8.

20. L.B. Zuev. Autowave processes of plastic flow localization in the actively deformed media // Physics of Metals and Metal Science. 2017, v. 118, N 8. p. 851860.

21. A.A. Presnyakov Localization of plastic deformation. Alma-Ata, 1981, p. 120.

22. A.A. Sorokin. Physicomechanical modeling of deformation and fracture of highly irradiated austenitic steels and development of methods for predicting the properties of materials for VVER internals: Ph. D. thesis, St. Petersburg, 2015.

23. I.A. Gindin et al. // FMM. 1978, v. 46(6), p. $1273-1277$.

24. I.A. Gindin, I.M. Neklyudov. Physics of software hardening. Kiev: "Naukova dumka", 1979, 184 p. 


\title{
ФОРМИРОВАНИЕ ПЛАСТИЧНЫХ СВОЙСТВ ВЫСОКООБЛУЧЕННОЙ НЕЙТРОНАМИ СТАЛИ 12Х18Н10Т
}

\author{
О.П. Максимкин, Д.А. Мережко, М.С. Мережко, К.Б. Сарсенбаева
}

Обсуждаются новые результаты экспериментов по изучению характера и закономерностей проявления эффекта аномально высокой пластичности аустенитных метастабильных облученных сталей, проанализированы возможные причины его образования и связь с «волной» деформации, сформулированы рекомендации по моделированию «волны».

\section{ФОРМУВАННЯ ПЛАСТИЧНИХ ВЛАСТИВОСТЕЙ ВИСОКООПРОМІНЕНОЇ НЕЙТРОНАМИ СТАЛІ 12Х18Н10Т}

О.П. Максимкін, Д.А. Мережко, М.С. Мережко, К.Б. Сарсенбаєва

Обговорюються нові результати експериментів з вивчення характеру і закономірностей прояву ефекту аномально високої пластичності аустенітних метастабільних опромінених сталей, проаналізовано можливі причини його утворення та зв'язок 3 «хвилею» деформації, сформульовані рекомендації з моделювання «хвилі». 